\title{
POSICIONAMENTO DOS ENFERMEIROS RELATIVO À REVELAÇÃO DE PROGNÓSTICO FORA DE POSSIBILIDADE TERAPÉUTICA: UMA QUESTÃO BIOÉTICA
}

\author{
Daniela Vivas dos Santos ${ }^{1}$ \\ Maria Cristina Komatsu Braga Massarollo ${ }^{2}$
}

Santos DV, Massarollo MCKB. Posicionamento dos enfermeiros relativo à revelação de prognóstico fora de possibilidade terapêutica: uma questão bioética. Rev Latino-am Enfermagem 2004 setembro-outubro; 12(5):790-6.

O estudo objetivou conhecer o posicionamento e a participação de enfermeiros frente à situação de informar o paciente sobre o prognóstico fora de possibilidade terapêutica. Fizeram parte do estudo 25 enfermeiros-chefe de um hospital geral, governamental e de ensino. Os dados foram coletados por meio de entrevistas e analisados quanti-qualitativamente, evidenciando os seguintes resultados: $40 \%$ dos enfermeiros não se posicionaram em relação a informar o paciente sobre 0 prognóstico fora de possibilidade terapêutica; $56 \%$ não tiveram qualquer participação na decisão de informar, ou não, o paciente. Ficou evidenciada a necessidade de os enfermeiros voltarem-se para questões bioéticas, que auxiliam a análise frente às situações dilemáticas.

DESCRITORES: bioética; enfermagem; prognóstico

\section{NURSES" ATTITUDE TOWARDS REVEALING THE PROGNOSIS OF NO TREATMENT POSSIBILITY: A MATTER OF BIOETHICS}

This study aims to get to know nurses' attitude and participation when they have to inform a patient about a prognosis of no treatment possibility. Twenty-five nurse practitioners from a general public school hospital took part in this study. Data were collected through interviews and were analyzed quantitatively and qualitatively, showing the following results: $40 \%$ of the nurses did not take a stand when informing about a prognosis of no treatment possibility; $56 \%$ did not take any part in the decision of informing the patient about the prognosis of no treatment possibility. This disclosed the need for nurses to consider bioethical matters, which can be of help in the analysis of dilemmas.

DESCRIPTORS: bioethics; nursing; prognosis

\section{POSICIONAMIENTO DE ENFERMEROS RESPECTO A LA REVELACIÓN DEL PRONÓSTICO FUERA DE POSIBILIDAD TERAPÉUTICA: UN ASUNTO BIOÉTICO}

El estudio tuvo como objetivo saber cuál sería el posicionamiento y la participación de enfermeros ante la situación de tener que informar al paciente sobre el pronóstico fuera de posibilidad terapéutica. Formaron parte del estudio 25 enfermeros jefes de un hospital general, gubernamental y de enseñanza. Los datos fueron recogidos através de entrevistas y luego analizados cuantitativa y cualitativamente, lo que evidenció los siguientes resultados: El $40 \%$ de los enfermeros no se posicionaron respecto a informar al paciente sobre el pronóstico fuera de posibilidad terapéutica, el 56\% no tuvo cualquier participación en la decisión de informar, o no, al paciente. Estos resultados revelaron que los enfermeros necesitan volcarse a cuestiones bioéticas, que ayudan en el análisis de situaciones dilemáticas.

DESCRIPTORES: bioética; enfermería; pronóstico

\footnotetext{
${ }^{1}$ Enfermeira, Assistente Técnico de Saúde I da Divisão de Oncologia do Hospital das Clínicas da Faculdade de Medicina da Universidade de São Paulo, e-mail: danivivas@hcnet.usp.br; ${ }^{2}$ Enfermeira, Professor Doutor da Escola de Enfermagem da Universidade de São Paulo, e-mail: massaro@usp.br
} 
INTRODUÇÃO

Os profissionais de saúde, na prática profissional, defrontam-se com situações dilemáticas e polêmicas, que envolvem o confronto dos seus valores com os valores de outras pessoas: pacientes, familiares, equipe de saúde, dentre outros.

Nessas situações, os valores do profissional sobre sua relação com o paciente, ou seja, de sujeito (profissional, que toma as decisões) e objeto (paciente, que sofre passivamente as ações) ou de sujeitos (profissional e paciente, este último, participante das decisões relativas ao seu tratamento e bem-estar), são fatores determinantes de suas ações ${ }^{(1)}$.

Para essas questões conflituosas, as respostas, quando existem, não derivam unicamente dos conhecimentos técnico-científicos, pois esses apenas oferecem subsídios para que cada pessoa, por meio da reflexão bioética, posicione-se frente aos dilemas, considerando os valores em conflito e interagindo com o "pensar ético" do grupo no qual está inserido ${ }^{(2)}$.

Atualmente, há interesse, por parte dos profissionais de saúde, em refletir sobre os conflitos éticos, morais e legais ${ }^{(2)}$, talvez porque a postura hipocrática, freqüentemente observada entre esses profissionais, esteja sendo, aos poucos, repensada, promovendo, assim, uma postura mais consciente, voltada para os valores, objetivos e necessidades do paciente.

Essa postura mais reflexiva cede espaço ao desenvolvimento do pensar que o homem é um ser multidimensional e que suas dimensões cultural, psíquica, social e espiritual são tão importantes quanto o aspecto técnico da assistência ${ }^{(2)}$.

Mesmo com a postura hipocrática sendo repensada, suas marcas ainda estão muito arraigadas no profissional de saúde, o que explica a sua conduta paternalista na relação com o paciente. No tocante à área da saúde, o paternalismo tem sido definido como condutas realizadas pelos profissionais as quais pretendem beneficiar pacientes ou clientes sem o consentimento deles, nas situações em que a ação do profissional envolve a violação de uma regra ética, legal e moral, no caso de o paciente ser competente e estar esclarecido para dar o consentimento ${ }^{(3)}$. Uma conseqüência decorrente dessa postura é a omissão para o paciente, total ou parcial, sobre o seu estado de saúde, principalmente quando esse é grave.
Uma questão que vem sendo muito discutida, e faz parte da polêmica que envolve a relação profissional de saúde - paciente, é: esclarecer ou não ao doente, portador de enfermidade com evolução fatal, que o seu tratamento é apenas paliativo, ou seja, que seu quadro está fora de possibilidades terapêuticas ${ }^{(4)}$.

Mesmo se baseando nos direitos legais e morais de o paciente receber a informação completa e verdadeira sobre sua condição, o profissional de saúde, ao vivenciar a situação de contar sobre o prognóstico fora de possibilidade terapêutica, tende a analisar qual a melhor alternativa para o paciente: informá-lo, ou não, sobre o prognóstico?

O fato de contar a verdade ao paciente significa que o reconhecimento de sua autonomia e liberdade prevaleceu sobre a fragilidade que a doença e a proximidade da morte podem provocar ${ }^{(5)}$. Entretanto, esse momento pode gerar estresse no profissional, pois a idéia de que a informação correta e completa alivia a angústia e a ansiedade, além de afastar a sensação de descaso, descuido e exclusão num momento de fragilidade e medo, frente à singularidade da situação vivenciada, contrapõese à possibilidade de o conhecimento da situação levar o indivíduo ao desespero extremo, tornando-o incapaz de decidir o que fazer, ficando ainda mais difícil essa delicada situação.

Deve-se, contudo, observar como a notícia é informada, porque, se for de modo abrupto, sem qualquer preparação e/ou assistência, contar a verdade pode ter conseqüências irreparáveis. Dessa maneira, o indivíduo deve ser assistido durante o processo de revelação do seu prognóstico, com direito a diálogos abertos, planejados, sistemáticos e individualizados ${ }^{(6)}$.

Diante do exposto, este trabalho pretende conhecer e discutir como, na prática, o enfermeiro se posiciona frente a essa situação.

\section{OBJETIVO}

Este trabalho teve como objetivo conhecer o posicionamento dos enfermeiros frente à situação de informar o paciente sobre o prognóstico fora de possibilidade terapêutica, identificando posturas, condutas, participação dos enfermeiros e interações multiprofissionais envolvidas nesse procedimento. 
MÉTODO

O presente estudo teve como cenário um hospital geral, de ensino e governamental, do Município de São Paulo, que se caracteriza por atender pacientes portadores de patologias com níveis de complexidade terciário e quaternário. Dessa forma, dos pacientes atendidos, muitos apresentam prognóstico fora de possibilidade terapêutica.

Para melhor compreensão dos resultados apresentados, vale ressaltar que o cenário utilizado é um Instituto de um Hospital considerado referência nas áreas de pesquisa, ensino e assistência. Esse Instituto subdivide-se em clínicas que podem assumir, diante de um dilema ético, a postura mais adequada às suas especificidades.

Fizeram parte da população do estudo 25 enfermeiros-chefe que, além das atividades administrativas, também prestam assistência direta a pacientes com prognóstico fora de possibilidade terapêutica e que concordaram em participar do estudo.

A opção por esses profissionais justifica-se por considerá-los com uma visão mais abrangente das situações ocorridas nas unidades de internação pelas quais respondem, por apresentarem maior poder nas tomadas de decisões relativas à atuação da enfermagem nessas unidades, do que os enfermeiros encarregados e assistenciais.

Após autorização da Instituição e aprovação pelo Comitê de Ética em Pesquisa e consentimento do Enfermeiro-Chefe, manifestado por meio da assinatura no Termo de Consentimento Livre e Esclarecido, os dados foram coletados por meio de entrevistas individuais, realizadas pela própria pesquisadora, utilizando um instrumento contendo questões abertas, que permitiram respostas mais completas e enriquecedoras sobre as experiências dos entrevistados relativas à assistência a pacientes em tratamento paliativo.

Os dados coletados foram agrupados e analisados quanti-qualitativamente, visto que a análise quantitativa permitiu a verificação da freqüência absoluta e relativa das respostas e a análise qualitativa permitiu explorar melhor o conteúdo dos relatos.

\section{RESULTADOS E DISCUSSÃO}

O grupo estudado, 25 enfermeiros-chefe, caracterizou-se por 24 (96\%) serem do sexo feminino, 13
(52\%) pertencerem à faixa etária de 40 a 49 anos, e 11 (44\%) terem entre 21 e 25 anos de profissão, condizendo com o perfil do profissional estudado.

No tocante ao posicionamento do enfermeiro referente a informar o prognóstico do paciente, 13 (52\%) afirmaram ser a favor, 2 (8\%) colocaram-se contra, e 10 (40\%) não se posicionaram claramente, alegando que dependia da situação vivenciada. Os dados demonstram que o assunto ainda é complexo, mas o paternalismo já cede espaço para posturas favoráveis ao conhecimento do paciente sobre sua doença, com alguns cuidados, como podemos observar nos trechos destacados:

O assunto é tão complexo e complicado que acabei me contradizendo

Eu acho que o paciente deve ficar sabendo, mas com ressalvas, para manter a esperança de uma possibilidade de vida, porque senão o indivíduo desiste rápido. É importante dizer a ele que a medicina avança muito rápido e que logo podem descobrir um novo tratamento para a doença. Se dizer que terapeuticamente não há mais chances para a cura e ponto, ele pode até se jogar da ponte.

Sou a favor de informar o paciente, pois é direito saber o que está acontecendo para deixar algo preparado. Entretanto, devese dar espaço para o indivíduo conversar, não falar muito e dar oportunidade para esclarecimento de dúvidas.

O paciente não deve ficar sabendo porque pode ficar mais deprimido, sempre tem esperança, principalmente a família.

Quanto à participação do enfermeiro no procedimento de informar o paciente, observou-se que é variável, pois profissionais que ocupam o mesmo cargo, por diversos motivos, apresentam diferentes atuações enquanto membros da equipe multiprofissional, pois, de acordo com os resultados, 14 (56\%) não tinham qualquer atuação e, na parcela participativa, 11 (44\%), as intervenções ocorriam de formas diferentes. Eis destacados, abaixo, trechos de entrevistas ilustrando melhor esses dados.

Não participo da decisão, o médico apenas comenta comigo a decisão já tomada.

Quem decide é o médico, mas intervenho no momento de contar, quando se faz necessário, pois solicito psicólogo para haver melhor preparo.

Eu não tenho participação nenhuma, pois aqui são muitos leitos, então não tenho tempo de participar das visitas e reuniões.

Aqui há visitas e reuniões com a equipe multidisciplinar semanalmente e, nesses momentos, todos os profissionais opinam. Há sete anos o médico era o dono do paciente e, atualmente, mudou bastante, havendo maior participação da equipe multiprofissional. 
No que se refere à avaliação da vontade do paciente em receber tal informação, verificou-se uma postura subjetiva, por não haver protocolo a ser seguido e depender, dentre outros fatores, de o enfermeiro estar atento ao comportamento do paciente e saber interpretálo. Entretanto, são citados vários obstáculos que aumentam a insegurança dos profissionais, por temerem piorar a qualidade de vida do paciente. São eles: a própria doença que interfere na comunicação; o baixo nível de compreensão; o estado emocional e o receio do paciente em achar que perguntar demais perturba o profissional, podendo, por isso, receber alta hospitalar "forçada". Em algumas clínicas, os pacientes recebem acompanhamento psicológico, com maior ou menor intensidade, dependendo da necessidade e da disposição do serviço; em outras, é rara a atuação desse profissional. No tocante a essa questão de informar o paciente, foi apontada a forte influência da postura do professor responsável pela clínica, ao ser referido que o procedimento não era realizado naquele setor, porque o professor era contra informar 0 paciente. A Tabela $1 \mathrm{e}$ algumas respostas corroboram 0 quadro apresentado.

Tabela 1 - Distribuição da população pelo modo de avaliar a vontade do paciente em receber tal informação. São Paulo. 2002

\begin{tabular}{lcc}
\hline \multicolumn{1}{c}{ Modo de avaliar a vontade do } & \multicolumn{2}{c}{ Enfermeiros } \\
paciente em saber o prognóstico & № & $\%$ \\
\hline Questionamento do paciente & 10 & 40 \\
Observação do estado emocional & 6 & 24 \\
Interferência da família na decisão & 3 & 12 \\
Profissional não soube informar & 2 & 8 \\
Outros & 4 & 16 \\
\hline Total & 25 & 100 \\
\hline
\end{tabular}

É difícil perceber, até pela própria patologia que dificulta a comunicação.

A rotatividade aqui é grande, o indivíduo percebe que todo mundo entra e sai e só ele permanece internado, então ele mesmo conclui que boa coisa ele não tem.

Ocorre a achologia. Observamos se ele pergunta sobre 0 diagnóstico ou tratamento.

Todos os pacientes têm acompanhamento psicológico e, quando há dúvida, há um acompanhamento psicológico mais intenso. Avalia-se o grau de ansiedade e nível de compreensão do indivíduo. Se o psicólogo conclui que o paciente não tem condições de ficar sabendo, a família é informada.
Considerou-se relevante verificar como o procedimento de informar é realizado e, mais uma vez, foi revelada a prevalência da opinião médica numa questão que diz respeito a toda equipe multiprofissional. Após análise dos relatos, observou-se que, cada vez mais, está sendo falado para o paciente sobre o seu diagnóstico e prognóstico. Além disso, apesar do uso freqüente de termos técnicos incompreensíveis para leigos, o paciente tem fácil acesso ao prontuário e papeleta, os quais ficam diariamente ao lado do leito, podendo ser lido a qualquer momento e, ainda, solicitar auxílio do profissional para esclarecimentos dos termos. Seguem abaixo a Tabela 2 e trechos das entrevistas que evidenciam tais dados.

Tabela 2 - Distribuição da população no tocante à forma de revelar o prognóstico ao paciente. São Paulo. 2002

\begin{tabular}{lcc}
\hline Formas de revelação do prognóstico & \multicolumn{2}{c}{ Enfermeiros } \\
& № & $\%$ \\
\hline Decisão apenas do médico & 10 & 40 \\
Equipe multiprofissional atua & 6 & 24 \\
Médico e enfermeira atuam & 4 & 16 \\
Médico e família atuam & 2 & 8 \\
Não é revelado & 2 & 8 \\
Médico e psicólogo atuam & 1 & 4 \\
\hline Total & 25 & 100
\end{tabular}

Quando necessário, utiliza o serviço de Psicologia geral, pois não há psicólogo específico para a unidade. Geralmente, o médico vai preparando o paciente, informando que o tratamento quimioterápico não deu o resultado que se esperava e que as condições do mesmo impede a realização de outro tratamento no momento.

Não há equipe, o médico entra sozinho e conversa com a família e o paciente. Há o profissional psicólogo, entretanto não há interação com a equipe.

Há discussão com toda a equipe multiprofissional e é esta mesma equipe que entra no quarto.

Este paciente recebe acompanhamento do psicólogo anterior à revelação e então o médico conta a verdade e depois do prognóstico revelado, a enfermeira também atua.

A equipe médica conta, o paciente não deglute, procura a enfermeira para chorar, muitas vezes é nessa hora que fico sabendo, informo sobre tratamentos paliativos. Tem psicólogo, mas é difícil, pois ela atende quatro clínicas, não consegue acompanhar. Nos casos mais críticos, eu mesmo a solicito. Solicito, também, orientação espiritual, se o mesmo pedir. 
Muitos médicos conversam com a família antes, porque ela orienta como proceder com aquele paciente: como contar, a hora certa e se deve contar. Entretanto, as condutas diferem de acordo com o médico.

Os dados referente às informações fornecidas, caso não seja revelada a informação real, é para saber quanto a informação transmitida ao paciente traduz a informação real. Nesse sentido, a postura ocidental diante do processo de morte, somada 'as tendências paternalistas, faz com que o paciente perca sua condição de sujeito, ocasionando mais um obstáculo nessa difícil situação: a relação não verdadeira com sua família e a equipe. Essa situação não anula os sinais da doença e nem permite um desconhecimento total do prognóstico, além de, muitas vezes, alimentar um estado aflitivo de dúvida por se evitar falar do assunto ${ }^{(2,4)}$.

Tabela 3 - Distribuição da população conforme informação fornecida ao paciente, caso não tenha sido revelado o prognóstico real. São Paulo. 2002

\begin{tabular}{lcc}
\hline \multicolumn{1}{c}{ Informação fornecida } & \multicolumn{2}{c}{ Enfermeiros } \\
& № & $\%$ \\
\hline Informação real & 7 & 28 \\
Nenhuma ou parcial & 6 & 24 \\
Seguirá tratamento em casa & 4 & 16 \\
$\begin{array}{l}\text { Tratamento não teve resultado } \\
\text { esperado e aguarda exames (que já }\end{array}$ & 3 & 12 \\
$\begin{array}{l}\text { estão prontos) } \\
\text { Paciente está bem }\end{array}$ & 2 & 8 \\
Outros & 3 & 12 \\
\hline Total & 25 & 100 \\
\hline
\end{tabular}

Há paciente que está morrendo, e o médico diz que está tudo bem e que vai ficar bem.

O paciente sempre fica sabendo a verdade.

Normalmente, eles justificam a alta do paciente porque o tratamento vai demorar muito, então vai fazer o tratamento em casa. Ou falam que o paciente está muito fraco e vai esperar o mesmo se recuperar para reinternar e operar. Eu fico sabendo dessas justificativas através dos pacientes, os médicos não dão satisfação nenhuma. Alguns pacientes chegam a comentar que não voltarão, porque estão muito fraco e sabem que não têm mais jeito.

Geralmente, alegam um outro motivo, desviam o assunto, informam que estão em dúvida quanto ao diagnóstico e vão verificar melhor os exames realizados dentro do Centro Cirúrgico, sendo que os resultados já estão prontos.

Informa-se que fará outro tratamento.
Geralmente esse paciente quase não pergunta. Os médicos não informam que o prognóstico é fechado e sim ruim. Vai do quanto ele consegue captar. Não há mentiras.

Por meio dos resultados apresentados, observouse que esse tema, revelação de prognóstico fora de possibilidade terapêutica, mesmo sendo uma situação comum dentro do hospital, é pouco abordada. Por esse motivo, talvez, as posturas sejam tão divergentes, e, na maioria das vezes, com pouco ou nenhum embasamento científico para lidar com o problema em questão, apoiandose apenas em experiências e valores pessoais. Entretanto, autores ${ }^{(2)}$ afirmam que o profissional deve estar preparado para viver essa situação porque foi treinado e, comumente, convive com ela. O paciente, muitas vezes, espera que os profissionais estejam capacitados para 0 enfrentamento dessa situação, visto que a manifestação da doença faz com que, direta ou indiretamente, ele procure o profissional por acreditar que apenas esse poderá ajudá-lo com as angústias, medos e problemas vividos $^{(2)}$. Todavia os enfermeiros se mostraram, em sua maioria, inseguros para essa vivência e sentem falta de um preparo que deveria ter início na graduação e prosseguir ao longo da vida profissional. Podemos observar nos trechos que, apesar de a morte ser um fato real e freqüentemente presente, ainda é cultuada como um evento artificial, inesperado e injusto.

Tabela 4 - Distribuição da população segundo os recursos utilizados para enfrentar essa situação. São Paulo. 2002

\begin{tabular}{lcc}
\hline \multicolumn{1}{c}{$\begin{array}{c}\text { Recursos utilizados para } \\
\text { enfrentamento da situação }\end{array}$} & \multicolumn{2}{c}{ Enfermeiros } \\
\hline Experiência própria & № & $\%$ \\
Palestras e leituras & 5 & 68 \\
Filosofia de vida & 2 & 20 \\
Acompanhamento psicológico & 17 & 8 \\
\hline Total & 25 & 100 \\
\hline
\end{tabular}

Leio alguns textos, de preferência os que são objetivos, não gosto daquele tipo de leitura abstrata e muitos textos que abordam esse tema são assim.

Utilizo minha experiência profissional para lidar com essa situação. Acredito que preciso de terapia porque faz parte da profissão se mostrar mais forte neste momento, entretanto este é um assunto que abala.

O recurso utilizado por mim para vivenciar esta situação é a minha experiência, na verdade eu detesto esta situação. 
Leituras, bom senso, instrução religiosa e crença.

Experiência pessoal. Acredito que há uma falta de preparo

de toda a equipe multiprofissional.

Experiência profissional. Há dificuldades para trabalhar com paciente terminal, pois o clima fica deprimente. Assisti algumas palestras sobre o assunto. Aqui não há suporte psicológico.

Preparo efetivo não tem, a Instituição não dá. Não busco, também. Às vezes há discussão em equipe com a psicóloga da clínica.

A questão sobre a vontade do profissional de receber esse tipo de informação, caso estivesse na condição de paciente, revelou a presença do sentimento de paternalismo do profissional enfermeiro, pois muitos que gostariam de ter conhecimento da verdade (88\%), para melhorar a qualidade de vida, são os mesmos que querem de alguma forma proteger o paciente dessa informação, considerada, por eles, maléfica. Esses dados estão de acordo com pesquisa ${ }^{(7)}$, na qual foram entrevistados 79 médicos e 118 adultos leigos. Em relação aos médicos, apenas $22 \%$ não usavam a "mentira piedosa", mas a grande maioria desejava ser informada da verdade para atender seus próprios interesses e os de suas famílias ${ }^{(7)}$. Uma parcela dos profissionais que ficaram indecisos quanto a informar ou não o paciente, gostaria de ser informada devido às justificativas destacadas nos relatos.

Gostaria de saber, porque tenho vontade de viver, então reagiria e recorreria a outros meios materiais, ou religiosos.

Gostaria de saber, porque, sabendo, eu teria vários caminhos a seguir, a escolher, e prepararia minha vida para a partida.

Gostaria de saber, pois já que tive a iniciativa de procurar o médico, o mínimo que espero como retorno são informações verdadeiras sobre minha saúde.

Gostaria de saber porque o paciente quando é da área da saúde é mais difícil a resposta evasiva, pois pega no ar. Gostaria de me preparar e participar.

Gostaria de saber, pois confiaria mais. Enquanto não fala se está tudo bem ou tudo mal, fico sem saber o que fazer.

Gostaria de saber, porque tenho de me preparar, tenho família, preciso deixar as coisa em ordem, as dívidas.

Não gostaria de saber, porque esse tipo de informação não me ajudaria em nada, ao contrário se ficasse sabendo não viveria com qualidade. Gostaria de saber uma segunda opinião, porque sem possibilidade de tratamento de cura num hospital pequeno é uma coisa, agora, fora de possibilidade terapêtica neste hospital é outra, pois isso significa que não há outro tratamento mesmo. Observa-se nesse relato uma contradição, pois, a priori, a profissional não queria saber, mas gostaria de ter uma segunda opinião e, para isso, precisa receber a notícia. Esse depoimento foi incluído no segundo grupo.

Não gostaria de saber, não tenho medo da morte, porém tenho receio de como seria dada essa informação, pois saber por uma pessoa que esteja preparada significa que a mesma te põe no buraco, mas estende a mão. Nós, latinos, somos muito emotivos e não dá para falar para o nosso povo da mesma maneira que se fala para um povo europeu.

\section{CONCLUSÃO}

Pelos resultados apresentados, concluiu-se que significativa parcela dos enfermeiros não se posicionou em relação a informar o paciente sobre o prognóstico fora de possibilidade de cura. A maioria não teve qualquer participação no processo de decisão de informar, ou não, o paciente, e os recursos utilizados pelos enfermeiros para vivenciar essa situação geralmente foram a experiência de vida. No entanto, quase a totalidade dos entrevistados gostaria de saber toda a verdade sobre o prognóstico, caso estivesse na condição de paciente.

Vale ressaltar que apenas uma pequena parcela dos enfermeiros fornece informações reais aos pacientes, referentes ao prognóstico. Os fatores que contribuem para isso são a influência da família e a postura adotada pelo médico responsável pela unidade de internação. Quanto às estratégias utilizadas nesse procedimento de informar, geralmente, variam de acordo com o médico, podendo esse atuar junto com a equipe multiprofissional e a família ou mesmo sozinho.

As condutas divergentes dentro de uma mesma Instituição podem indicar um momento de transição de uma conduta paternalista para uma conduta mais participativa, fazendo-se necessário, para isso, a equipe multiprofissional estruturar-se para adequar a conduta de acordo com os interesses do paciente.

Desse modo, os interesses do paciente devem ser analisados criteriosamente por meio da realização da comunicação terapêutica, que engloba querer ouvir o paciente sobre seus valores relacionados ao processo de morte, perspectiva de vida, religião, o modo como os sintomas da doença e dos tratamentos o afetam, dentre outras posturas. Para isso não é suficiente apenas um profissional conversar com o paciente uma única vez, sendo fundamental a interação da equipe multiprofissional por meio de reuniões periódicas e efetivas a fim de obter- 
se a visão holística do paciente. Apesar de ocupar um tempo, muitas vezes escasso, do profissional, é válido ressaltar a importância do diálogo como uma das principais condutas terapêuticas a ser desenvolvida nesse momento, por motivos já explicitados anteriormente neste trabalho.

O enfermeiro apresenta dois importantes papéis nessa situação, o de ter maior contato com o paciente e sua família, estabelecendo um maior vínculo, inclusive de confiança e liberdade com esses, e o de ser articulador de uma equipe multiprofissional, pois permanece maior tempo na unidade em relação aos outros profissionais, permitindo, assim, o encontro com eles. Dessa forma, fica evidenciada a necessidade de os enfermeiros voltaremse para questões bioéticas relacionadas, entre outros assuntos, a direitos do paciente, autonomia, beneficência e não-maleficência, visto que esses conceitos auxiliam para nortear uma conduta individualizada e consciente, permitindo uma postura adequada da equipe multiprofissional frente a dilemas como esse, o que pode diminuir o estresse vivenciado por todos nessas situações.

\section{REFERÊNCIAS BIBLIOGRÁFICAS}

1. Segre M, Cohen C. Bioética. São Paulo (SP): EDUSP; 1995. 2. Pessini L, Barchifontaine $C$ de $P$. Problemas atuais de Bioética. 4a ed. São Paulo (SP): Loyola; 1997.

3. Häyry H. Paternalism. Encyclopedia Appl Ethics 1998; 3:44957.

4. Carvalho MVB, Franco ACR. Uma experiência de ensino sobre a relação paciente fora de possibilidade de cura: enfermeira em nível de graduação. Prática Hospitalar 1999; 1(5):47-54.

5. Oliveira $A C$, Fortes $P A$. de $C$. O direito à informação e a manifestação da autonomia de idosos hospitalizados. Rev Esc Enfermagem USP 1999; 33(1):59-65.

6. Boemer MR, Sampaio MA. O exercício da enfermagem em sua dimensão bioética Rev Latino am Enfermagem 1997; 5(2):33-8

7. Pan Chacon J, Kobata CM, Liberman SPC. A "mentira piedosa" para o canceroso. Rev Assoc Med Bras 1995; 41(4):274-6. 